\title{
The effect of topical application of red betel (piper crocatum) leaf gel on clinical attachment level to treat patients with chronic periodontitis
}

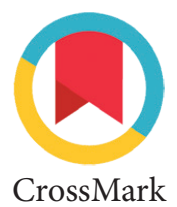

Herryawan*

\section{Abstract}

Objective: The purpose of this study is to determine the effect of red betel (piper crocatum) leaf gel as adjunctive therapy of scaling and root planning to the clinical attachment level (CAL) repair in the treatment of chronic periodontitis.

Material and Methods: This study was conducted using randomized control trial, single-blind, split-mouth method before and after treatment. The study participants were 18 patients afflicted with chronic periodontitis and aged between 30 and 62 years. During the study, the jaws of the subjects were divided into two sides for test and control. Although both sides were treated for scaling and root planning, the side for the test was given additional topical application of red betel leaf gel. The evaluation of CAL was performed 1 month after the treatment. The data were statistically analyzed using the paired $t$ test for comparison before and after treatment on each side and the unpaired $t$ test to compare the test and control side.

Results: Improvement of CAL in the test side is better than the control side, while distobuccal test side showed the greatest improvement by $31.4 \%$.

Conclusion: Topical application of red betel leaf gel in patients with chronic periodontitis can increase the clinical attachment level.
Department of Periodontology, Faculty of Medicine, Jenderal Achmad Yani University, Cimahi, Indonesia

*Corresponding to: Herryawan, Department of Periodontology, Faculty of Medicine, Jenderal Achmad Yani University, Cimahi, Indonesia

herryawan@lecture.unjani.ac.id

Received: 21 February 2017 Revised: 9 0ctober 2017 Accepted: 16 0ctober 2017 Available online: 1 December 2017

Keywords: Chronic periodontitis, Clinical attachment, Gel, Red betel, Topical applications

Cite this Article: Herryawan. 2017. The effect of topical application of red betel (piper crocatum) leaf gel on clinical attachment level to treat patients with chronic periodontitis. Journal of Dentomaxillofacial Science 2(3): 160-163. D0I: 10.15562/jdmfs.v2i3.610

\section{Introduction}

Chronic periodontitis is the most common form of periodontitis associated with the accumulation of plaque and calculus. Generally, it has a slow rate of progression and causes moderate periodontal tissue damage, although a more rapid period of destruction may occur. Increased development of chronic periodontitis may be caused by the impact of local factors, including systemic or environmental factors, affecting the normal interaction between host and bacteria. ${ }^{1}$

Scaling and root planning are an integral and fundamental mechanical procedure critical to the success of all periodontal treatments. The treatment is done by removing plaque, calculus, endotoxins, and also necrotic cementum on the root surface to get the root surface biologically acceptable, reducing pocket depth, clinical attachment level repair, as well as preparing the gingival tissue for surgical treatment. ${ }^{2,3}$ However, sometimes the retention of plaque is persists in remote locations during the treatment. This could create a space for reestablished infection due to the growth of microflora and cause periodontal disease. Therefore, pharmacotherapeutic agents are used as additional methods for periodontal diseases prevention., ${ }^{4,5}$

Use of pharmacotherapeutic agents as an adjunctive therapy in controlling periodontitis is categorized based on the type of administration used, that is, whether local or systemic. ${ }^{3,4}$ The potential risks associated with systemically antibiotic therapy include bacterial resistance, emergence of opportunistic infections and the possibility of allergies, while the long-term administration of NSAIDs may also have harmful effects such as indigestion and bleeding, kidney and liver damage, central nerve system disorders, inhibition of platelet aggregation, prolonged bleeding time, bone marrow damage and hypersensitivity reactions. ${ }^{3}$ Local antibiotics are shown to provide some benefits, such as delivering the drug to the area of disease activity at concentrations of bactericide and allowing long-term administration of drugs. The administration of chemotherapeutic agents in a controlled manner into the periodontal pocket can alter the flora pathogens and improve clinical signs of periodontitis. ${ }^{3-6}$ Some of antibacterial agents applied locally include acrylic strips, and fiber and gel formulations. The use of gel itself has been proven to be more efficient and effective, as it does not need to be removed or repeated. ${ }^{7}$

Today, the popularity of herbal therapy is on the rise. One of the herbs that are empirically used as traditional medicine is red betel (piper crocatum). This plant is widely known as an ornamental plant 
that grows vines on the fence or tree. Several studies have been conducted to reveal the benefits of red betel and show that red betel leaves contain essential oils that have antibacterial properties. ${ }^{8}$ In addition to essential oils, red betel leaf also has beneficial chemical compounds such as alkaloids, saponins, tannins and flavonoids that have antibacterial and anti-inflammatory properties. ${ }^{9,10}$

In regard to the above mentioned benefits, efficiency and efficacy, ${ }^{7}$ the writer IS interested to examine the effect of topical application of red betel leaf gel as a supporting treatment for scaling and root planning in patients with chronic periodontitis ${ }^{3-6}$ based on the parameter of clinical attachment level (CAL) before and after treatment.

\section{Material and methods}

The study used red betel leaves taken from the red betel plant that grows in Bandung. The red betel leaf gel was manufactured in the Laboratory of Pharmacy Faculty of Science Jenderal Achmad Yani University Cimahi Indonesia. There are two phases in preparing the red betel leaf gel: a. Preparing the dried extract of red betel leaf and $b$.

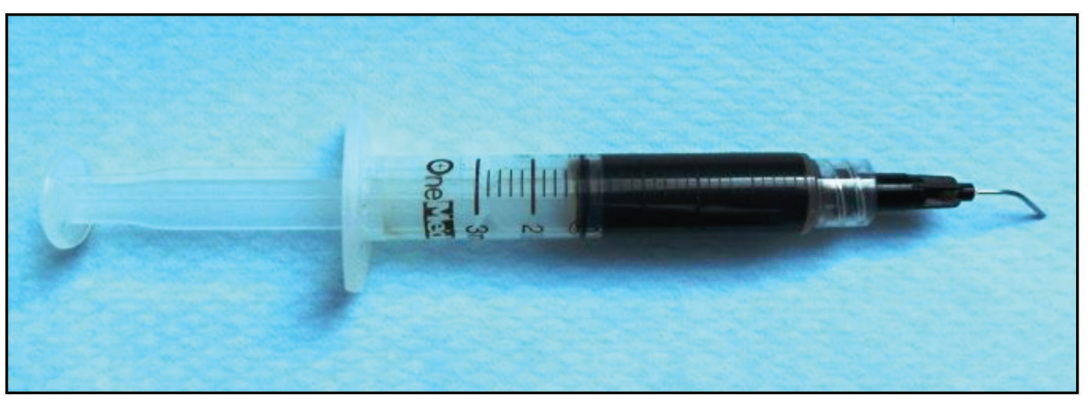

Figure 1 Red betel leaf gel has been placed in a syringe

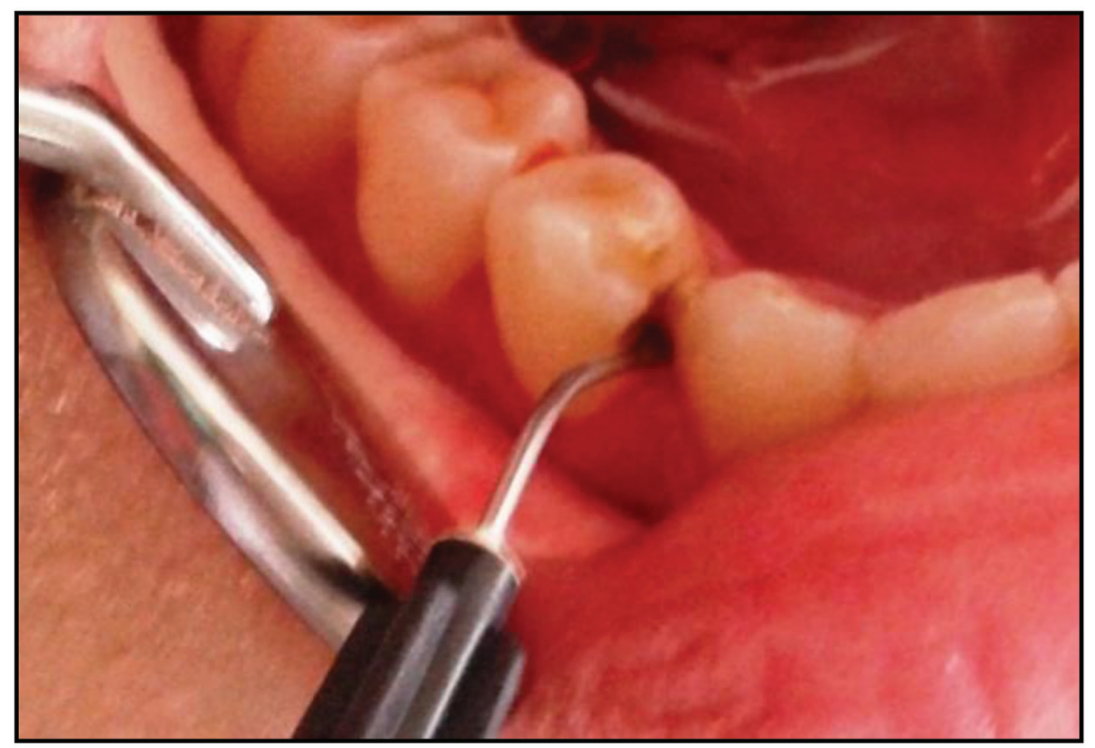

Figure 2 Application of red betel leaf gel into the periodontal pocket preparing the red betel leaf gel figure 1 so that every 10 grams of the resultant gel contains $10 \%$ of red betel leaves.

The study used a randomized controlled trial, single-blind, split-mouth method before and after treatment, ${ }^{12}$ and involved the trial of 18 patients with chronic periodontitis who came to the Clinic of Periodontal Unjani Cimahi between September and December 2016. These participants were selected purposively. The inclusion criteria for the participants of this study were men and women aged $\geq 30$ years who suffered from chronic periodon-titis on at least two opposite jaw sides, ${ }^{12,13}$ while those with a history of systemic diseases, smoker, past periodontal treatment of at least 6 months prior to the study, taking the antibiotic at least 3 months prior to the study, and wearing dentures also fixed orthodontic appliance were excluded from the study. ${ }^{14-17}$

The study was conducted after obtaining approval from the ethics committee. Patients who were eligible for the study were first asked to sign an informed consent form. Their jaws were then divided into two sides. One side for the test area that was treated with scaling and root planning and also topical application of red betel leaf gel and the other side, that is, the control side, was given scaling and root planning treatments only figure $2 .{ }^{12}$ During the study, the red betel leaf gel was applied to the bottom of the pocket until it overflowed to the gingival margin and left for a few moments before the excess gel was cleaned with cotton. Subjects were instructed not to eat, drink, or rinse for 1 hour after treatment. ${ }^{4,5}$ They were also instructed to maintain their daily oral hygiene routine.

Measurement of CAL was recorded at the baseline and 1 month after the treatment. A week after treatment, during a control visit, researcher reapplied red betel leaf gel on the test side., ${ }^{4,5}$ Data analysis using paired $t$ test was conducted to measure CAL changes before and after treatment on each side, while the unpaired T-test was performed to compare the test and control side, with a $95 \%$ confidence level. ${ }^{18}$

\section{Results \\ Characteristics of Sample}

Table 1 shows that 18 patients aged between 30 and 62 years with chronic periodontitis participated in the study. Most respondents were male (5 or $27.7 \%$ from the total number of samples) and were in the age group of 50-59 years.

\section{Clinical Attachment Level}

Table 2 shows that the improvement of CAL is significant in all surfaces, except on the buccal and mesiobuccal areas of the control side. CAL significantly improved, by as much as $31.4 \%$, on the test 
Table 1 Characteristics of sample

\begin{tabular}{lcc}
\hline \multirow{2}{*}{ Age Range } & \multicolumn{2}{c}{ Sex } \\
\cline { 2 - 3 } & Male & Female \\
\hline $30-39$ & $3(16.6 \%)$ & $1(5.5 \%)$ \\
$40-49$ & $1(5.5 \%)$ & $2(11.1 \%)$ \\
$50-59$ & $5(27.7 \%)$ & $2(11.1 \%)$ \\
$60-69$ & $2(11.1 \%)$ & $2(11.1 \%)$ \\
\hline
\end{tabular}

Table 2 Average value of CAL before and after treatment

\begin{tabular}{|c|c|c|c|c|c|}
\hline \multirow{2}{*}{ Surface Side } & & \multicolumn{3}{|c|}{ CAL } & \multirow[b]{2}{*}{ P-Value } \\
\hline & & Before & After & Difference & \\
\hline \multirow{2}{*}{ Distobuccal } & Test & 6.17 & 4.22 & $1.94(31.4 \%)$ & $0.000^{*}$ \\
\hline & Control & 6.11 & 5.56 & $0.56(9.2 \%)$ & $0.006^{\star}$ \\
\hline \multirow{2}{*}{ Buccal } & Test & 4.28 & 3.33 & $0.94(22.0 \%)$ & $0.000^{*}$ \\
\hline & Control & 4.06 & 3.78 & $0.28(6.9 \%)$ & 0.311 \\
\hline \multirow{2}{*}{ Mesiobuccal } & Test & 6.00 & 4.72 & $1.28(21.3 \%)$ & $0.000^{\star}$ \\
\hline & Control & 5.50 & 5.17 & $0.33(6.0 \%)$ & 0.131 \\
\hline \multirow{2}{*}{ Distolingual } & Test & 6.22 & 4.83 & $1.38(22.2 \%)$ & $0.000^{\star}$ \\
\hline & Control & 5.89 & 5.22 & $0.67(11.4 \%)$ & $0.012^{\star}$ \\
\hline \multirow{2}{*}{ Lingual } & Test & 5.06 & 4.06 & $1.22(24.1 \%)$ & $0.002^{\star}$ \\
\hline & Control & 4.83 & 4.33 & $0.50(10.4 \%)$ & $0.007^{\star}$ \\
\hline \multirow{2}{*}{ Mesiolingual } & Test & 5.83 & 4.44 & $1.33(22.8 \%)$ & $0.000^{\star}$ \\
\hline & Control & 5.22 & 4.78 & $0.44(8.2 \%)$ & $0.046^{\star}$ \\
\hline
\end{tabular}

* significant $(\mathrm{p}<0.05)$.

Table 3 Average differences of CAL before and after treatment

\begin{tabular}{lcccc}
\hline \multirow{2}{*}{ Surface } & \multicolumn{3}{c}{ CAL } & \\
\cline { 2 - 4 } & Test Side & Control Side & Difference & P-Value \\
\hline Distobuccal & 1.94 & 0.56 & $1.38(74.2 \%)$ & $0.001^{*}$ \\
Buccal & 0.94 & 0.28 & $0.66(70.2 \%)$ & $0.002^{\star}$ \\
Mesiobuccal & 1.28 & 0.33 & $0.95(71.1 \%)$ & $0.001^{*}$ \\
Distolingual & 1.38 & 0.67 & $0.71(51.4 \%)$ & $0.016^{*}$ \\
Lingual & 1.22 & 0.50 & $0.72(59.0 \%)$ & $0.010^{*}$ \\
Mesiolingual & 1.33 & 0.44 & $0.89(66.9 \%)$ & $0.004^{\star}$ \\
\hline
\end{tabular}

${ }^{*}$ significant $(\mathrm{p}<0.05)$. theory that chronic periodontitis mostly affects adults only. ${ }^{1,10}$ Results show that there is improvement of CAL on both sides, which was observed in the case of all respondents who received initial periodontal treatments such as scaling and root planning. The initial treatment itself was aimed at eliminating as much as possible the etiologic factor in the form of microbes or other factors causing periodontal disease, so as to stop the progression of the disease and repair the periodontal tissues for a healthy mouth. ${ }^{13,19}$ This kind of treatment is also done for controlling the bacteria that cause periodontal abnormalities and local risk factors and also for minimizing the potential impact of systemic factors. Changes in microflora after scaling and root planning are usually accompanied by changes in the measurement of clinical periodontal tissue. ${ }^{19}$ Several clinical trials have consistently shown that scaling and root planning will reduce gingival inflammation and probe depth and that it will also improve CAL in most patients with periodontal diseases. ${ }^{2,3}$

Comparison of changes on the buccal and mesiobuccal regions of the control side before and after treatment showed that there was no significant improvement. This result may have been caused by several things, such as remote tooth's surface, the difference in the operator's ability to scaling and root planning, as well as the possibility of bacterial invasion into the soft tissue or dentin tubules. In this case, mechanical therapy cannot treat all subgingival deposits or reach the bacteria that may have attacked soft tissue or dentin tubules. The low improvement may also be a result of a re-colonization of pathogenic bacteria originating from non-dental $\operatorname{area}^{4,5,13}$ in the treated region. As for the test side, compared to the control side, there was a significant improvement in all surfaces, both before and after treatment. This result was due to the application of red betel leaf gel, which has antibacterial and anti-inflammatory effects, on the test side, as an adjunct of initial treatment. Local application of antibacterial agent can be chosen as an adjunct to initial therapy to control the growth of bacteria on the membrane barrier. When placed into the periodontal pocket, the agent will be able to reduce the amount of subgingival microflora, pocket depth, and clinical signs of inflammation, while local additional therapy will result in better CAL than is possible with scaling and root planning only., ${ }^{413}$ The administration of antibacterial agents locally can be used as an adjunct therapy to conventional mechanical therapy. In the case of periodontitis, an antibacterial agent that is applied locally to the subgingival would be 
very useful for treating patients who have a pocket depth of $5 \mathrm{~mm}$ or more, bleeding on probing and also who are unresponsive to primary therapy, including scaling and root planing.

\section{Conclusion}

The topical application of red betel leaf gel after scaling and root planning in patients with chronic periodontitis enhances the clinical attachment level better than the treatment option of using scaling and root planning only.

\section{Conflict of Interest}

The author report no conflict of interest.

\section{References}

1. Kotsilkov K, Dimitrov R. Complex treatment in a patient with severe chronic periodontitis (case report). J IMAB 2015;21: 687-689.

2. Ryan ME. Nonsurgical approaches for the treatment of periodontal disease. Dent Clin N Am 2005;49: 611-636.

3. American Academy of Periodontology. Treatment of plaque-induced gingivitis, chronic periodontitis and other clinical conditions. J Periodontol 2001;72: 1790-1800.

4. Goodman $\mathrm{CH}$, Robinson PJ. Periodontal therapy: reviewing subgingival, irrigation and future consideration. JADA 1990;121: 541-543.

5. Isaac AV, Mathew JJ, Ambooken M, et al. Management of chronic periodontitis using subgingival irrigation ozonized water: a clinical and microbiological study. JCDR 2015;9: 29-33.

6. Killoy WJ, Cobb CM. Controlled local delivery of tetracycline in the treatment of periodontitis. Compendium 1992;13: 1150-1154.

7. Magnusson I. The use of locally delivered metronidazole in the treatment of periodontitis, clinical result. J Clin Periodontol 1998;25: 959-963.
8. Marliyana SD, Handayani N, Ngaisah S. Antibacterial activities of essential oils red betel leaves. J Chem Research ALCHEMY 2013;9: 33-40.

9. Lister INE, Viany RD, Nasution AN, et al. Antimicrobial activities of methanol extract of red betel (piper crocatum) leaf. J Chem and Pharm Research 2014;6: 650-654.

10. Fitriyani A, Winarti L. Anti-inflammatory test of red betel (piper crocatum ruiz \& pav) leaf methanol extract in white rats. Trad Med J 2011;16: 34-42.

11. Nisa GK, Nugroho WA, Hendrawan Y. Extraction of red betel leaf (piper crocatum) methods Microwave Assisted Extraction (MAE). JBKT 2014;2: 72-78.

12. Lesaffre E, Philstrom B, Needleman I, Worthington H. The design and analysis of splitmouth studies: what statisticians and clinicians should know. Statis Med 2009;28: 3470-3482.

13. Carranza FA, Forrest JL, Jepsen S, et al, editors. Carranza's clinical periodontology. 12th ed. St. Louis: Elsevier Saunders; 2015. p. 34-491

14. Haq MW, Tanwir F, Tabassum S, et al. Association of periodontitis and systemic diseases. Int J Dent Oral Health 2015;1: 1-7.

15. Ta'a MA. The effects of smoking on periodontal disease: An evidence-based comprehensive literature review. OJST 2014;4: 33-41.

16. American Academy of Periodontology. Parameter on periodontal maintenance. J Periodotol 2000;71: 849-850.

17. Anand AJ, Karthikeyan R, Annapoorani S. Iatrogenic factors affecting periodontium. JIDENT 2015;2: 1-6.

18. Kim TK. T-test as a parametric statistic. Korean J Anesthesiol 2015;68: 540-546.

19. Aljateeli M, Koticha T, Bashutski J, et al. Surgical periodontal therapy with and without initial scaling and root planing in the management chronic periodontitis: a randomized clinical trial. J Clin Periodontol 2014;41: 693-700.

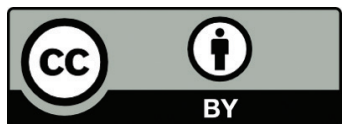

This work is licensed under a Creative Commons Attribution 